\title{
Effects of food-particle size and pelletization on individual growth and larval settlement of the deposit feeding polychaete Capitella capitata Type I*
}

\author{
Neal W. Phillips** and Kenneth R. Tenore ${ }^{* * *}$ \\ Skidaway Institute of Oceanography, P. O. Box 13687, Savannah, Georgia 31416, USA
}

\begin{abstract}
Three size classes of Capitella capitata (Type I) were fed 4 size ranges of detritus particles derived from red seaweed Gracilaria foliifera. Growth was generally reduced when only the largest particle-size range (150 to $250 \mu \mathrm{m})$ was available, and the effect was most pronounced for small worms. Worms lost weight when fed fecal pellets comparable in size to the largest particles of seaweed detritus. They also lost weight when fed sonically-disnupted fecal pellets, even though most worms consumed disaggregated fecal pellets and some ingested intact pellets. Larval settlement rates were positively correlated with food-particle size for seaweed detritus, but settlement was poor on fecal pellets. Fecal pellets did not inhibit settlement on an attractive substrate (cereal flakes). Thus, the effects of pelletization of ingested materials on growth and larval settlement probably reflect nutritional limitations rather than particle size effects.
\end{abstract}

\section{INTRODUCTION}

The potential production of deposit feeders is determined in great part by the nutritional quality of food. The food resources that can by utilized by deposit feeders vary greatly in biochemical composition so that the particulate organics in sediments, whether they be freshly sedimented detritus, reworked fecal pellets, or microalgae, will differ in nutritional quality and thus in potential for supporting the growth of deposit feeders (Tenore, 1981, 1984; Tenore et al., 1982).

However, not all detritus in sediments is physically available to deposit feeders. Sediment consists of particles differing in size, shape, and texture as well as nutritional value. Feeding and tube-building activities can lower the abundance of fine particles (Rhoads, 1974) and result in larger particles not available for

- This research was supported in part by the Ocean Science Division of the National Science Foundation (Grant OCE82-00385), USA

- Present address: Continental Shelf Associates, Inc., P. O. Box 3609, Tequesta, Florida 33458, USA

-. Present address: Chesapeake Biological Laboratory, P. O. Box 38, Solomons, Maryland 20688, USA ingestion by a given size of animal. Pelletization of sediment has been proposed as a factor limiting deposit feeder production (Levinton and Lopez, 1977; Levinton et al., 1977) and as a cause for the 'crash' of populations of opportunistic polychaetes (Grassle and Grassle, 1974). The proposed limiting effects of pelletization are presumably due to both nutritional and particle size effects (Hargrave, 1976; Levinton, 1979). but the physical packaging of sediment into noningestible pellets has been explicitly considered as a possible limiting factor (Levinton and Lopez, 1977; Levinton et al., 1977; Levinton, 1979). Furthermore, several non-microbial factors can affect the physical integrity of fecal pellets, including animal feeding and locomotory activity (Frankenberg and Smith, 1967). physical abrasion due to currents (Risk and Moffatt, 1977), and swelling due to initial uptake of water (Lautenschlager et al. 1978). Thus, the effects of pelletization per se deserve consideration. This paper reports the effects of particle size and food pelletization on growth and larval settlement of a deposit feeding polychaete.

Experiments were conducted using the deposit feeding polychaete Capitella capitata Type I (Grassle and 
Grassle, 1976). This opportunistic species is characteristic of organic rich environments, where it frequently reaches abundances of $10^{4}$ individuals $\mathrm{m}^{-2}$ (Grassle and Grassle, 1974). Particle size in the gut contents of field-collected $C$. capitata has been examined by Whitlatch (1980), and effects of food nutritional value on individual growth and population have been described by Tenore $(1977,1981,1984)$.

\section{METHODS}

\section{Growth experiments}

Groups of 20 to 30 worms of 3 sizes ( $\mathrm{small}=0.3 \mathrm{mg}$ wet weight $[\mathrm{WW}$, medium $=0.6 \mathrm{mg} \mathrm{WW}$, and large $=$ $1.5 \mathrm{mg}$ WW, per worm) were removed from stock culture tanks, picked clean of adhering sand, blotted dry, and wet-weighed. The worms were then added to plastic dishes $\left(0.005\right.$ or $0.012 \mathrm{~m}^{2}$ depending on worm size) containing $1 \mathrm{~cm}$ of clean, fine $(<300 \mu \mathrm{m})$ sand. The number of worms of a given size was chosen to yield a density of $2.5 \mathrm{~g} \mathrm{WW}$ worms $\mathrm{m}^{-2}$; larger dishes were used for large worms. A ration of $6 \mathrm{~g}$ dry weight (DW) $\mathrm{m}^{-2} \mathrm{~d}^{-1}$ was provided to each dish, except where noted below. This food ration insured that the quantity of food did not limit growth (Tenore, 1984). Worms were left in the culture dishes for about $42 \mathrm{~h}$, a time period chosen to insure measurable growth increments and to minimize changes in food particle size. The worms were then removed from the dishes, picked clean, and reweighed. Average daily weight-specific growth rate $(G)$ of the worms was estimated from the weight change of these experimental populations as:

$$
\mathrm{G}=\frac{(\text { Final } \mathrm{WW}-\text { Initial } \mathrm{WW})}{(\text { Average } \mathrm{WW}) \times(\text { time })} \times 100
$$

Two sets of growth experiments were conducted. In the first, the 3 different sizes of worms were cultured on 4 particle-size ranges $(<38 \mu \mathrm{m}$ [geometric mean of $33 \mu \mathrm{m}], 38$ to $75 \mu \mathrm{m}, 75$ to $150 \mu \mathrm{m}, 150$ to $250 \mu \mathrm{m}$ ) of detritus derived from the red seaweed Gracilaria foliifera. Seaweed was grown in outdoor culture tanks (Lapointe, 1981), freeze-dried, and ground in a Wiley mill. The ground, dried seaweed was sieved to obtain the 4 particle-size ranges. Worms of given sizes (3 replicate dishes per treatment) were grown on the 4 particle size ranges during the same experimental period to minimize blocking effects due to any differences in initial worm condition.

The second set of growth experiments examined the nutritional value and availability for ingestion of fecal pellets produced by Capitella capitata. Medium-sized worms were grown on equivalent nitrogen rations of mixed cereal or fecal pellets from worms fed on mixed cereal. The fecal pellets, collected by pipette from an established worm culture, could have ranged in age from minutes to weeks. A portion of the pellets was placed in scintillation vials and disrupted by brief (30 s) immersion in an ultrasonic water bath. The average dimension of intact pellets was $218 \pm 63 \mu \mathrm{m}$ by $124 \pm 34 \mu \mathrm{m}(\mathrm{SD}, \mathrm{n}=50)$. Sonification produced disaggregated masses of fecal material rather than discrete particles. Worms were also grown on mixed cereal, fecal pellets from the culture tank, and 'old' fecal pellets from a culture tank that had not been fed for over $3 \mathrm{mo}$.

To determine whether the worms would ingest intact or sonically disrupted fecal pellets, we starved worms for $12 \mathrm{~h}$ in dishes containing a layer of fine sand, then added intact or sonically disrupted pellets. Approximately 20 worms were removed from each dish after 2 to $4 \mathrm{~h}$ and examined under a dissecting microscope to determine whether they had ingested the material.

We also examined the ability of medium-sized worms to ingest $<38 \mu \mathrm{m}$ and 150 to $250 \mu \mathrm{m}$ seaweed detritus. Worms were starved for $12 \mathrm{~h}$ in dishes containing a layer of fine sand. Labelled $\left({ }^{14} \mathrm{C}\right)$ seaweed detritus (Tenore et al., 1979) was sieved to obtain the 2 size fractions. Fifteen $\mathrm{mg}$ of each particle size fraction was added to each dish. Individual dishes were terminated after 1 or $2 \mathrm{~h}$ feeding periods by pouring the contents into an enamel pan containing $10 \% \mathrm{HCl}$. The worms were picked clean of adhering sand grains and detritus, rinsed with distilled water, and dried at $70^{\circ} \mathrm{C}$ for $48 \mathrm{~h}$. Worms and samples of unused food were weighed to the nearest $1 \mu \mathrm{g}$ using a Mettler analytical balance and then combusted in a Packard sample oxidizer. The specific activity of worms was corrected for background and for oxidizer and counter efficiency, then divided by the specific activity of the food to estimate the amount ingested.

\section{Settlement experiments}

Larval settlement assays were conducted using the methods of Chesney and Tenore (1984). Plastic dishes $\left(0.001 \mathrm{~m}^{2}\right)$ containing $1 \mathrm{~cm}^{3}$ of fine sand and $15 \mathrm{mg} \mathrm{DW}$ of food were placed on a Plexiglas stand about $10 \mathrm{~cm}$ off the bottom of a large worm culture tank. The dishes were exposed for 24 or $48 \mathrm{~h}$ to larvae present in the culture tank and transferred to clean trays containing aerated, $1 \mu \mathrm{m}$ filtered seawater for $24 \mathrm{~h}$ to allow sufficient growth to facilitate counting. Larvae were counted by spreading the contents of the settlement dish out in large, gridded Petri dish and examining the substrate at $12 \times$ magnification. The substrates compared were: 
Experiment I: $30 \mathrm{mg} \mathrm{dish}^{-1}$ of each of the 4 different particle-size ranges of seaweed detritus;

Experiment II: Mixed cereal (15 $\mathrm{mg} \mathrm{DW}^{\mathrm{dish}}{ }^{-1}$ ), pellets from mixed cereal (15 $\mathrm{mg}^{\mathrm{DW}}$ dish $\left.^{-1}\right)$, or pel-

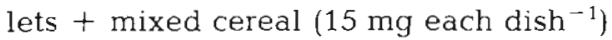

Experiment III: $15 \mathrm{mg}$ dish of intact or sonically disrupted pellets.

In each experiment, 3 replicate dishes of each substrate and 2 control dishes containing no food were counted. Samples of worm fecal pellets were also incubated in filtered seawater to determine whether larvae were present in the material added to the settlement dishes. No larvae were found in these dishes.

Because larvae were counted after $24 \mathrm{~h}$, results may reflect some initial post-settlement mortality as well as settlement rates; however, no dead larvae were seen when the contents of the settlement dishes were examined under a dissecting microscope.

\section{Analysis of foods}

Mixed cereal flakes, worm fecal pellets and the 4 particle-size ranges of seaweed detritus were analysed for organic carbon, nitrogen, and caloric content; bacterial abundances on seaweed detritus and fecal pellets were also determined. Seaweed detritus was first incubated for $1 \mathrm{~d}$ in filtered seawater to parallel the treatment of food offered to the worms. These samples were rinsed with distilled water and freezedried. Percent ash-free dry weight (AFDW) was determined by weight loss upon ignition at $470^{\circ} \mathrm{C}$ for $4 \mathrm{~h}$. Carbon and nitrogen contents of duplicate samples were measured using a Perkin-Elmer Model 240 Elemental Analyser. Caloric content was determined by microbomb calorimetry and available caloric content by hydrolysis in weak acid (Tenore, 1981). Bacterial abundance was estimated by fluorescence microscopy (Hobbie et al., 1977). Weighed subsamples of foods were preserved in $5 \%$ formalin in scintillation vials; bacteria were dislodged from particle surfaces by ultrasonic treatment ( 2 min) in a sonifying water bath. Samples were kept on ice during the disruption to prevent heating. Previous experience in our laboratory shows that this treatment removes about $90 \%$ of attached bacteria. Duplicate $10 \mathrm{ml}$ aliquots of diluted $(1: 100)$ sample were incubated for $15 \mathrm{~min}$ with acridine orange and filtered as described by Hobbie et al. (1977). Ten fields or at least 200 bacteria were counted per slide.

\section{Statistics}

Growth-rate data were analysed without transformation using parametric statistics, because: (1) the values are average weight gains of about 20 worms, and averages tend to be normally distributed even if their component values are not (central limit theorem); (2) there was no significant correlation between variance and mean. Growth rates for treatments that could be ordered (i.e. particle sizes of food) were analysed using simple and polynomial regression to obtain the best fit. Geometric-mean particle sizes for each size class of food were used as the independent variables for regression. For treatments that could not be ordered (different foods), results were compared using one-way ANOVA and the Student-Newman-Keuls multiple comparisons test (Sokal and Rohlf, 1969).

Larval settlement data were log-transformed to reduce heteroscedasticity, then analysed using regression (for orderable treatments) or ANOVA as for the growth rate data.

Other statistical analyses are cited as necessary in the results section. The significance level for all analyses was 0.05 .

\section{RESULTS}

\section{Effects of particle size on growth}

Growth rates of small and medium worms were negatively related to geometric-mean particle size of the food, although the form of the relation appeared to vary depending on worm size (Fig. 1). The effect was most notable for small worms fed the largest particle size of seaweed destritus. The relation was not significant for large worms.

The different size fractions of the detritus were similar in biochemical composition, except that the smallest particle-size range had higher ash levels and correspondingly lower levels of carbon, nitrogen, and calories (Table 1). The largest size fraction had lower nitrogen levels than the other size fractions but the nitrogen content compares favorably with those of foods that produce excellent growth (Tenore, 1984). Bacterial abundance was higher on the smallest size fractions (Table 1). No formal attempt was made to incorporate these differences in food composition into the statistical analyses of growth rate differences.

\section{Growth rates on fecal pellets}

Medium-sized worms lost weight when fed the fecal pellets of worms grown on cereal. Weight loss was the same when the pellets were sonically disrupted (Fig. 2). The nitrogen content of the fecal pellets (Table 1), and therefore the supply rate of nitrogen to worms fed fecal pellets, was similar to that for worms fed mixed cereal; however, the latter grew at about $19 \%$ 


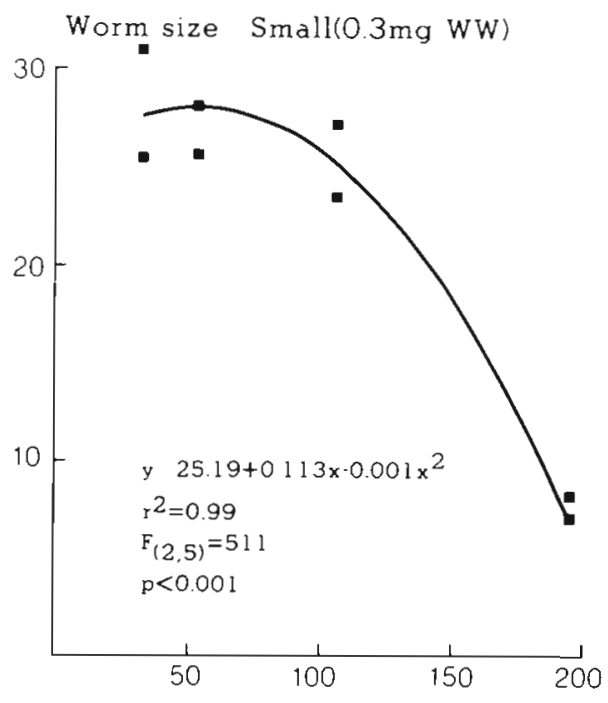

Worm size Medium(0.6mg WW)
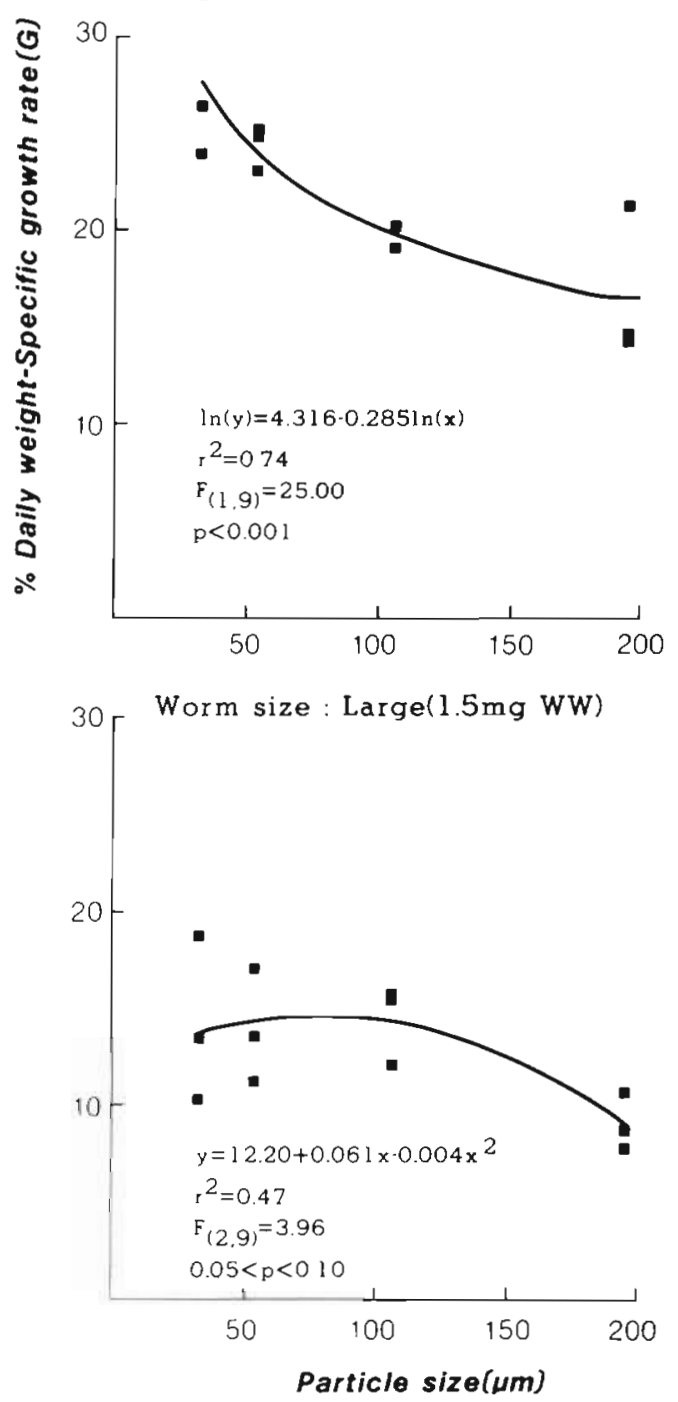

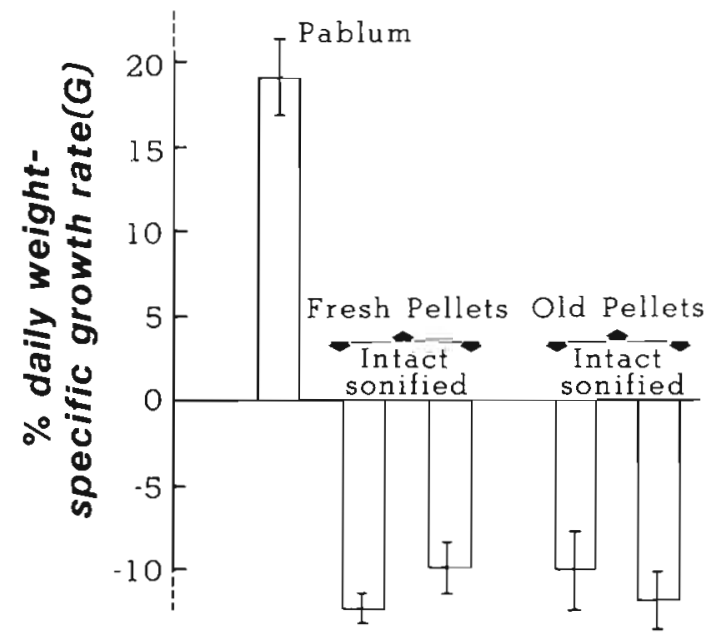

Fig. 2. Capitella capitata. Daily weight-specific growth rates of worms fed pablum (Gerber's mixed cereal) vs. old or fresh, intact or sonically disrupted worm fecal pellets. Values are means \pm 1 standard error (SE); number of observations (n) was 3 for all treatments. Results for all fecal pellet treatments are not significantly different from each other at $p>0.10$ using the Student-Newman-Keuls (SNK) multiple comparisons test

$\mathrm{d}^{-1}$ (Fig. 2). Protein and other primary amines exclusive of chitin (estimated by the fluorescamine assay following alkaline hydrolysis; Castell et al. 1979), accounted for essentially all fecal pellet nitrogen (assuming $\mathrm{N}=$ protein/6.25). In related experiments (results not shown), increasing the supply rate of sonified fecal pellets offered to worms had no effect on growth rates.

Worms lost weight at comparable rates when fed 'old' and 'new' pellets. Sonic disruption of the pellets had no effect on weight loss (Fig. 2). The composition of the 'old' fecal material was similar to that of the fresher pellets, except that bacterial densities were about 4 times higher on the former.

\section{Ingestion of fecal pellets and seaweed detritus}

When starved worms were offered fecal pellets, $35 \%$ had ingested some pellets after 2 to $4 \mathrm{~h}$. In contrast, $62 \%$ of the worms offered sonified fecal pellets ingested them (proportions significantly different at $p<0.05$ using the G-test for heterogeneity of categori-

Fig. 1. Capitella capitata. Daily weight-specific individual growth rates of different sizes of worms fed equal rations of different particle sizes of detritus derived from seaweed. Each value represents a growth rate determination for a group of 20 to 35 worms, depending on worm size; biomass density and ration were equivalent for all treatments. Food-particle sizes are plotted as geometric-mean size within a given size range 
Table 1. Chemical composition of different particle-size ranges of seaweed detritus and worm fecal pellets used in growth and larval settlement experiments. Values are means of 2 determinations, except for AFDW (n $=3$ ). All percentages refer to dry weight. Coefficients of variation ( $\mathrm{SD} / \mathrm{x}$ ) were approximately $1 \%$ for caloric and AFDW values, $2.5 \%$ for $\mathrm{N}$ values, $0.5 \%$ for $\mathrm{C}$ values, and $7 \%$ for the bacterial counts (between slide variation). AFDW $=$ Ash-free dry weight

\begin{tabular}{|c|c|c|c|c|c|c|}
\hline & $\%$ AFDW & $\% \mathrm{C}$ & $\% N$ & $\begin{array}{l}\text { Calories } \\
\mathrm{mg}^{-1} \mathrm{DW}\end{array}$ & $\begin{array}{c}\% \text { Calories } \\
\text { available }\end{array}$ & $\begin{array}{c}\text { Bacteria } \\
\mathrm{mg}^{-1} \times 10^{7}\end{array}$ \\
\hline \multicolumn{7}{|c|}{ Seaweed size fraction: } \\
\hline $38 \mu \mathrm{m}$ & 88.3 & 37.7 & 4.08 & 3.62 & $38^{\circ}$ & 2.28 \\
\hline $38-75 \mu \mathrm{m}$ & 93.4 & 40.8 & 4.13 & 3.83 & $38^{\circ}$ & 0.81 \\
\hline $75-150 \mu \mathrm{m}$ & 92.9 & 40.7 & 4.26 & 3.71 & $38^{\circ}$ & 1.16 \\
\hline $150-250 \mu \mathrm{m}$ & 93.2 & 40.0 & 3.75 & 3.79 & $38^{\circ}$ & 1.14 \\
\hline Pablum & 97.0 & 42.6 & 2.60 & 3.99 & 54 & - \\
\hline 'Fresh' fecal pellets & 37.9 & 14.5 & 2.33 & 1.45 & 22 & 0.17 \\
\hline 'Old' fecal pellets & 40.4 & 16.6 & 2.31 & - & - & 0.62 \\
\hline
\end{tabular}

cal data; Sokal and Rohlf, 1969). Disrupted fecal material was eventually re-pelletized by the worms.

Table 2 shows the results of the ${ }^{14} \mathrm{C}$-uptake experiment using the smallest and largest particle size fractions of detritus derived from seaweed. Fewer worms

Table 2. Results of ${ }^{14} \mathrm{C}$ uptake experiment using small $(<38$ $\mu \mathrm{m})$ and large $(150$ to $250 \mu \mathrm{m})$ particles of seaweed detritus. About 25 medium-sized worms $(0.5 \mathrm{mg}$ WW) were used in all treatments. Ingestion given as amount ( $\mu \mathrm{g} \mathrm{DW}$ ) ingested per worm $\pm 1 \mathrm{SD}$; only labelled worms were included in the ingestion calculation. Number of observations given in parentheses

\begin{tabular}{|lcccc|}
\hline & \multicolumn{5}{c|}{ Particle-size range } \\
& $1 \mathrm{~h}$ & $2 \mathrm{~h}$ & $1 \mathrm{~h}$ & $2 \mathrm{~h}$ \\
\hline & & & & \\
& & & & $150-250 \mu \mathrm{m}$ \\
Percent of worms & 52 & 79 & 0 & 17 \\
labelled & 5.64 & 5.25 & 0 & 1.75 \\
Ingestion & \pm 1.67 & \pm 0.99 & & \pm 1.50 \\
& $(12)$ & $(19)$ & $(9)$ & $(4)$ \\
\hline
\end{tabular}

feeding on the large particles were labelled significantly and the uptake rate of labelled worms was lower when they were fed the large particles.

\section{Effects of particle size on larval settlement}

Larval settlement rate was positively correlated $\left(\mathrm{r}^{2}=\right.$ $0.42, \mathrm{n}=12$; both settlement rate and particle size were log-transformed) with the particle size of seaweed detritus (Fig. 3). The explanation for this result is unknown and the effect deserves further investigation.

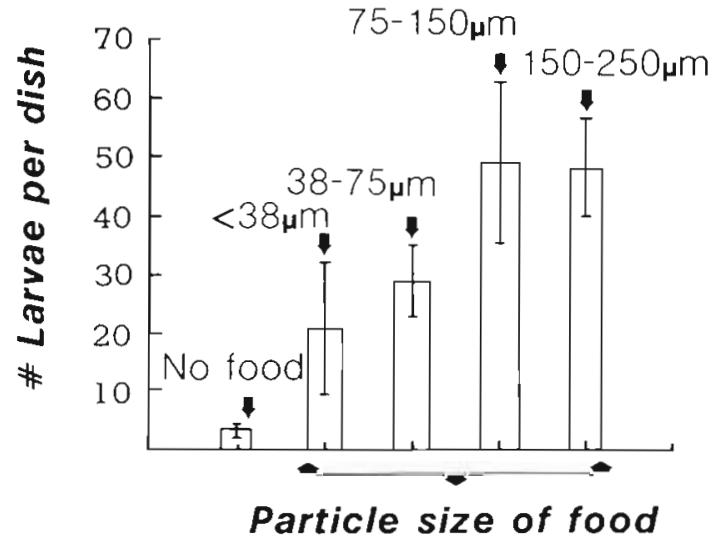

Fig. 3. Capitella capitata. Larval settlement rates on different particle-size ranges of red seaweed detritus. Values are means $\pm 1 \mathrm{SE}$ and $\mathrm{n}=3$ for each treatment. Dish size: 0.0012 $\mathrm{m}^{2}$. Amount of food per dish: $30 \mathrm{mg} \mathrm{DW}$. Control is significantly lower than all other treatments (SNK test), and larval settlement is significantly correlated with geometric mean particle size $\left(\mathrm{r}^{2}=0.42, \mathrm{p}<0.05\right.$; both variables were logtransformed for the calculation)

The result does show that fecal pellets should not, simply because of their size, induce poor settlement.

\section{Responses of larvae to fecal pellets}

Larval settlement dishes containing fecal pellets from adult worms did not attract significantly more larvae than control dishes containing no food (Fig. 4). Dishes with $15 \mathrm{mg}$ of cereal and $15 \mathrm{mg}$ of fecal pellets attracted about the same number of larvae as did dishes with $15 \mathrm{mg}$ of cereal only. Thus, although fecal pellet did not attract larvae, they apparently did not inhibit settlement. Settlement was also not affected by prior sonic disruption of the fecal pellets (Fig. 5). 


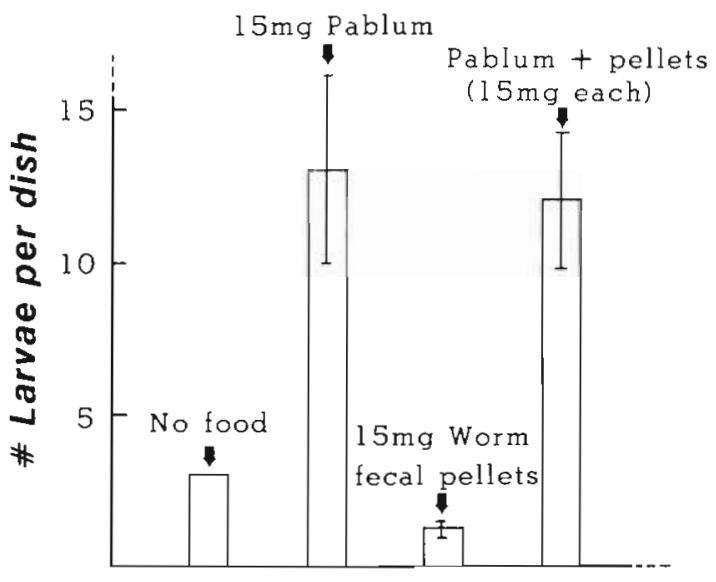

Fig. 4. Capitella capitata. Larval settlement rates on pablum $(15 \mathrm{mg})$, fecal pellets $(15 \mathrm{mg})$, or a combination of both $(15 \mathrm{mg}$ each). Values are means $\pm 1 \mathrm{SE} ; \mathrm{n}=3$ observations per treatment (except $n=2$ for controls). Rates for control and fecal pellets alone are not significantly different. Rates for pablum and pablum with pellets are not significantly different from each other but are higher than the other treatments

(SNK test, log-transformed larval settlement rates)

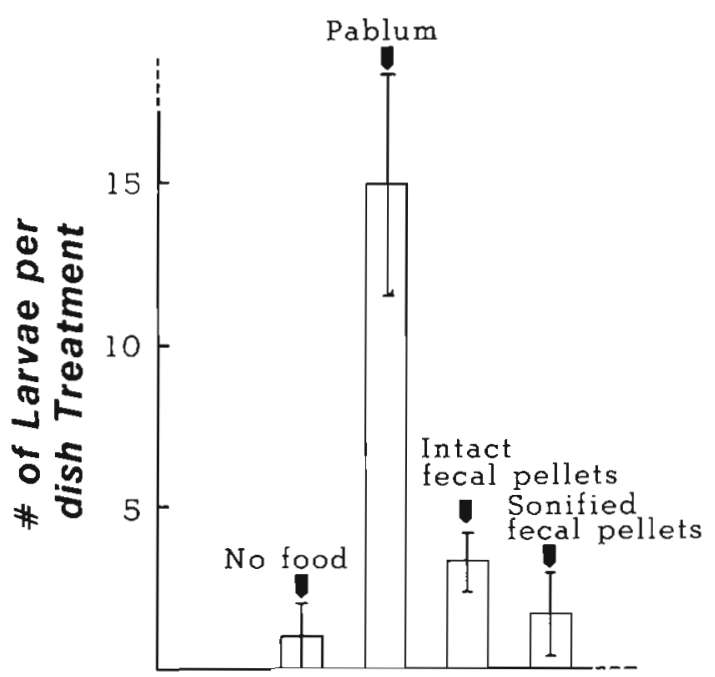

Fig. 5. Capitella capitata. Larval settlement rates on pablum, intact fecal pellets, or sonified fecal pellets. Amount of food per dish: $15 \mathrm{mg}$ DW. Values are as for Fig. 4. Control (no food) and pellet treatments are not significantly different (SNK test, log-transformed larval settlement rates)

\section{DISCUSSION}

Fecal pellets and large particles of an otherwise nutritious food, when fed to Capitella capitata, yielded lower growth rates than did smaller particles. Fecal pellets were not an attractive substrate for larval settlement. We suggest that although particle size limitations can influence worm growth rates, weight loss on fecal pellets is due to nutritional limitations and is not simply the consequence of 'packing' materials into large, unavailable particles. These findings have important implications for the regulation of deposit feeder populations.

The inability of Capitella capitata to handle and ingest large particles, evidenced by limited feeding on intact fecal pellets and by the results of the ${ }^{14} \mathrm{C}$ uptake experiments, is not surprising. Sediment in the guts of field-collected $C$. capitata is dominated by particles $<10 \mu \mathrm{m}$ in diameter (Whitlatch, 1980), although this result may reflect the dominance of fine particles in the area where the worms were collected. C. capitata feeds by everting a sac-like pharynx (Fauchald and Jumars, 1979) and lacks the biting or browsing abilities of deposit feeding mud snails (Lopez and Kofoed, 1980) and corophild amphipods (Nielsen and Kofoed, 1982) that allow the latter 2 to exploit large particles.

Differences in the effects of particle-size variation on the growth of 3 size classes of worms could reflect a greater ability of large worms to handle some large particles. However, large worms grow and metabolize more slowly, per unit weight, than small worms and should therefore be less dramatically affected by reduced food availability.

One would expect worms to grow poorly on fecal pellets because pellets are large particles. However, some worms consumed intact fecal pellets, and worms that were supplied with disaggregated pellets consumed the material but lost weight. When worms were fed fecal pellets, weight losses were approximately the same as for starved worms (about 10\% per day; Tenore, unpubl.). Worms apparenty derived little or no nutritional value from the feces. Fecal pellets had high nitrogen content $(2.3 \%)$ and a low $\mathrm{C} / \mathrm{N}$ ratio (6). Most of the nitrogen was proteinaceous. Caloric content was low (1.45 cal $\left.\mathrm{mg}^{-1} \mathrm{DW}\right)$, however, and the available calories (Tenore, 1981) were lower than in other foods (Table 1). Presumably, most of the labile organic matter is digested during passage of food through the gut, leaving a substrate low in nutritional value.

Our results show that physical disruption of fecal pellets does not necessarily produce a food source that can support deposit feeder growth. One may question the meaning of such results on the basis that models of deposit feeder resource limitation have included both microbial recolonization and pellet disintegration as controlling factors (Levinton and Lopez, 1977; Levinton, 1979); one can postulate that only pellets of some particular 'age' would be nutritious. However, in our experiments, when worms were fed disaggregated pellets of a wide range of possible ages, they essentially starved. Recycled fecal organic matter, at least that produced from readily assimilable foods, is not a likely food source for the worms. Fecal pellets derived from more refractory detritus (e.g., vascular plant material) 
would contain organic matter that is not readily assimilable by deposit feeders and that could be transformed by microbial activity into substrates that would be assimilable upon reingestion.

Some researchers have suggested that deposit feeding populations in nature can be limited by complete pelletization of surficial sediments - i.e. by the standing stock of ingestible material (Grassle and Grassle, 1974; Levinton and Lopez, 1977). We agree that the availability of ingestible sediment can be a proximal cause for the limitation of such populations. However, recycled fecal material is not the only source of ingestible particles. Sedimentation from the water column (Hargrave, 1980; Zeitzschel, 1980) contributes organic matter that is likely to be more utilizable by deposit feeders than is previously processed sediment. The best predictor of growth rate and maximum attainable biomass of laboratory populations of Capitella capitata is the supply rate of organic nitrogen as new food (Tenore, 1977, 1981, 1984). Although this finding does not preclude any contribution by recycled fecal pellets, the present experiments suggest that the presence of previously uningested food is necessary for growth and larval settlement. The relative importance of recycled pellets, newly-deposited organic matter, and benthic microalgae as food sources and substrates for larval settlement is likely to vary depending on the nature of the detrital food sources available and the biology of the particular deposit feeding population (Tenore et al., 1982).

\section{LITERATURE CITED}

Castell, J. V., Cervera, M., Marco, R. (1979). A convenient micromethod for the assay of primary amines and proteins with fluorescamine. A reexamination of the conditions of reaction. Analyt. Biochem. 99: 379-391

Chesney, E., Tenore, K. R. (1984). Oscillations of laboratory populations of the polychaete Capitella capitata Type I: their cause and implications for natural populations. Mar. Ecol. Prog. Ser. (submitted)

Fauchald, K., Jumars, P. A. (1979). The diet of worms: a study of polychaete feeding guilds. Oceanogr. mar. Biol. Rev. 17: 193-284

Frankenberg, D., Smith, K. L. (1967). Coprophagy in marine animals. Limnol. Oceanogr. 12: 443-450

Grassle, J. F., Grassle, J. P. (1974). Opportunistic life histories and genetic systemsin marine benthic polychaetes. J. mar. Res. 32: 253-284

Grassle, J. P., Grassle, J. F. (1976). Sibling species in the marine pollution indicator Capitella (Polychaeta). Science, N. Y. 192: 567-569

Hargrave, B. T. (1976). The central role of invertebrate feces in sediment decomposition. In: Anderson, J. M., MacFadyen, A. (ed.) The role of terrestrial and aquatic organisms in decomposition processes. 17th Symp. Brit. Ecol. Soc. Blackwell, London, p. 301-321

Hargrave, B. T. (1980). Factors affecting the flux of organic matter to sediments in a marine bay. In: Tenore, K. R.,
Coull, B. C. (ed.) Marine benthic dynamics. University of South Carolina Press, Columbia, p. 243-263

Hobbie, J. E., Daley, R. J., Jasper, S. (1977). Use of nuclepore filters for counting bacteria by fluorescence microscopy. Appl. environ. Microbiol. 33: 1225-1228

Lapointe, B. E. (1981). The effects of light and nitrogen on growth, pigment content, and biochemical composition of Gracilaria foliifera v. angustissima (Gigartinales, Rhodophyta). J. Phycol. 17: 90-95

Lautenschlager, K. P., Kaushik, N. K., Robinson, J. B. (1978). The peritrophic membrane and faecal pellets of Gammarus lacustris limnaeus Smith. Freshwat. Biol. 8: $207-211$

Levinton, J. S. (1979). Deposit-feeders, their resources, and the study of resource limitation. In: Livingston, R. J. (ed.) Ecological processes in coastal and marine systems. Plenum, New York, p. 117-141

Levinton, J. S., Lopez, G. R. (1977). A model of renewable resources and limitation of deposit-feeding benthic populations. Oecologia 31: 177-190

Levinton, J. S., Lopez, G. R., Lassen, H. H., Rahn, U. (1977). Feedback and structure in deposit-feeding marine benthic communities. In: Keegan, B. F., O'Ceidigh, P., Boaden, P. J. S. (ed.) Proceedings of the 11 th European Symposium on Marine Biology, Galway. Pergamon Press, Oxford, p. 409-416

Lopez, G. R., Kofoed, L. H. (1980). Epipsammic browsing and deposit-feeding in mud snails (Hydrobiiadae). J. mar. Res. 38: $585-599$

Nielsen, M. V., Kofoed, L. H. (1982). Selective feeding and epipsammic browsing by the deposit-feeding amphipod Corophium volutator. Mar. Ecol. Prog. Ser. 10: 81-88

Rhoads, D. L. (1974). Organism-sediment relations on the muddy sea floor. Oceanogr. mar. Biol. A. Rev. 12: 263-300

Risk, M. J., Moffatt, J. S. (1977). Sedimentological significance of fecal pellets of Macoma balthica in the Minas Basin, Bay of Fundy. J. sedim. Petrol. 47: 1425-1436

Sokal, R. F., Rohlf, F. J. (1969). Biometry: The principles and practice of statistics in biological research. W. H. Freeman, San Francisco

Tenore, K. R. (1977). Growth of Capitela capitata on various levels of detritus derived from different sources. Limnol. Oceanogr. 22 (5): 936-941

Tenore, K. R. (1981). Organic nitrogen and caloric content of detritus. I. Utilization by the deposit-feeding polychaete, Capitella capitata. Estuar. coast. mar. Sci. 12: 39-47

Tenore, K. R. (1984). Organic nitrogen and caloric content of detritus. III. Effect on growth of a deposit-feeding polychaete, Capitella capitata. Estuar. coast. Shelf Sci., in press

Tenore, K. R., Cammen, L. M., Findlay, S. E. G., Phillips, N. (1982). Perspectives of research an detritus: do factors controlling the availability of detritus to consumers depend on its source? J. mar. Res. 40: 473-490

Tenore, K. R., Hanson, R. B., Dornseif, B. E., Wiederhold, C. N. (1979). The effect of organic nitrogen supplement on the utilization of different sources of detritus. Limnol. Oceanogr. 24: 350-355

Whitlatch, R. B. (1980). Patterns of resource utilization and coexistence in marine intertidal deposit-feeding communities. J. mar. Res. 38: 743-765

Zeitzschel, B. (1980). Sediment-water interactions in nutrient dynamics. In: Tenore, K. R., Coull, B. C. (ed.) Marine benthic dynamics. University of South Carolina Press, Columbia, p. 195-218 